\title{
Conference Report: Libraries in the Digital Age (LIDA 2018), Zadar, Croatia, 13-15 June 2018
}

The biennial conference "Libraries in the Digital Age" (LIDA 2018) http://ozk. unizd.hr/lida/ was held for the 15th time in Zadar (Croatia). This biennial conference is organized by three partnering institutions: the Department of Information Sciences, University of Zadar, the Department of Information Sciences, University of Osijek (Croatia) and the School of Communication and Information, Rutgers University (USA). This year's theme was "Social Justice, Community Engagement and Information Institutions: Access, Diversity, and Inclusion".

Since the year 2000, the conference deals with topics around information and heritage institutions and challenges they are facing in the digital environment always keeping in touch with current issues emerging in information sciences. LIDA 2018 gathered almost 160 academics and practitioners from the (L)IS and related fields, from 24 countries (Australia, Bosnia and Herzegovina, Bulgaria, Canada, Chile, Croatia, Czech Republic, Denmark, Finland, France, Germany, Great Britain, Hungary, India, Ireland, Jordan, Lithuania, New Zealand, Norway, Slovenia, Sweden, Switzerland, Turkey, and USA). The conference program offered almost 50 lectures, workshops, posters, doctoral forum, student showcase and panel discussions.

Among many interesting lectures, our attention was drawn to those with the topics of critical librarianship, activism in libraries (i.e. society) and role of the libraries and other information institutions in the contemporary democratic society, human rights and the position of the minorities in the information profession itself, library services for marginalized users (people experiencing homelessness, prisoners, refugees, migrants, members of the LGBTIQ community, ethical and linguistic minorities, etc.). Another important and current topic covered in the LIDA 2018 was fake news.

LIDA 2018 had two keynote speakers, Nicole A. Cooke from the University of Illinois at Urbana-Champaign (USA) and Toni Samek from the University of Alberta (Canada). In her talk, Nicole A. Cooke noted that librarians should be active bystanders, by being aware of the role they are playing in their surroundings, meaning they should be able to determine if action is required when they witness social injustice taking place. Librarians should have responsibility to act and intervene safely if necessary. Cooke concluded that social justice is about educating ourselves and others and taking actions to change current situation. Toni Samek in her keynote, addressed issues regarding enforcing human rights in everyday work. She also pointed out how librarians can be involved in fighting for marginalized members of the society, for example in changing copyright laws for people with reading disabilities. 
Human rights and Library Science and Information Science became more connected in recent years which she proved by showing results of the database searching of the topics.

Since LIDA is known for giving great support to students, there were several segments of the conference for them. The doctoral forum gave opportunity to three doctoral students to present their doctoral thesis in front of three international jury members who gave them constructive comments and objective feedback. Undergraduate and graduate students presented their projects in a session called Student Showcase where a financial award was given to the winners by anonymous donors and supporters of LIDA students. The Doctoral form and student showcase were sponsored by the OCLC. In the poster session, most of the posters were student's work under auspices of their mentors. Altogether, there were about 30 doctoral, master and bachelor students from Bosnia and Herzegovina, Croatia, Germany, Ireland, and USA. Most of Croatian and $\mathrm{BiH}$ students were working as volunteers to help to run the conference smoothly. Award winning Best student's poster was "Tagging in Online News Articles” presented by L. Kraljev, A. Grgeč and D. Cupar from the Department of Information Sciences, University of Zadar, Croatia and the award winning paper from the Student showcase was "Public Library Space Assessment from Librarians and Patrons' Perspective: The Case of the City and University Library in Osijek” presented by V. Filić, T. Vilček and M. Paradžik from the Department of Information Sciences, University of Osijek, Croatia. This paper won 500 Euros.

In the last 18 years, since the first conference was organized in collaboration with Croatian and American University professors in the field of Information Sciences, Tatjana Aparac Jelušić and Tefko Saracevic, we can proudly say that LIDA has become a recognized and well attended conference in the field of library and information science, not only in Croatia, but in the world as well. LIDA 2018 had a well balanced program hosting lectures from theoretic/academic perspectives and practice as well giving the opportunity to all participants to establish collaborations, exchange and develop ideas and stay on top of the current issues in the field and the society itself. LIDA participants always had positive feedback on the friendly and informal atmosphere during breaks and social events. LIDA participants consider themselves members of the LIDA family.

LIDA 2018 was held under the auspices of the Association for Information Science \& Technology (ASIST), Croatian Library Association, and Croatian Information and Documentation Society. ASIST has been supporting LIDA from its beginnings, and ASIST/European Chapter became more engaged with LIDA from 2010 onwards.

By Drahomira Cupar Department of Information Sciences University of Zadar Croatia E-mail: dcupar@unizd.hr 